\title{
Green Anaconda (Eunectes murinus) with Bacterial Clinical Stomatitis
}

\author{
Nathana Beatriz Martins', Lucas Arthur Ricardo Ferreira', André Luiz Quagliatto Santos', \\ Rafael Rocha de Souza', Thaís de Almeida Moreira', Jean Henrique Nunes de Paula², \\ Caroline Lopes Queiroz ${ }^{3}$ \& Anna Monteiro Correia Lima ${ }^{3}$
}

\begin{abstract}
Background: Stomatitis is an infectious disease common in serpents and responsible for high mortality rates. It is characterized by the infection of the oral mucosa and neighboring tissues, related to the opportunistic character of bacteria present in the normal microbiota, pathogenic in stressful situations. Few studies have described the profile of sensibility of these agents in serpents of the Brazilian fauna. Therefore, this study has aimed at describing the isolation and identification of the infectious agents involved in the clinic stomatitis in a specimen of green anaconda (Eunectes murinus), and the profile of sensibility and resistance to antimicrobial agents.

Case: The serpent has been rescued in an urban environment, without previous records and featured erosive injuries in its oral cavity, with the presence of secretion. In a clinical evaluation, it has been assessed that the specimen had erosive injuries in its oral cavity, with hyperemic points in its mucosa and serous secretion. Then the specimen went through a collection of the secretion from its oral cavity for microbiological analysis. Typical colonies of Enterococcus, Citrobacter and Enterobacter were identified by the colony morphology and their typical odor. The results of these tests were able to confirm and identify the Citrobacter freundii, Enterobacter and Enterococcus species. The profile of sensibility to antimicrobials of the isolated microorganisms has been determined through the method of diffusion in the disk of Kirby-Bauer. There was not any sensitive antimicrobial for the three agents. For treatment, based on the antimicrobial profile presented, was used Ciprofloxacin ${ }^{\circledast}$ associated to daily washings with solution of chlorhexidine $0.12 \%$ for 10 days. Clinical cure was observed at the end of this treatment.

Discussion: Despite the high frequency of this disease in the clinical routine of snakes, little information about pathogen agents affecting constrictor serpents in their native area is available. Immunodepression, malnutrition, and temperatures and humidity outside the animal thermal comfort zone, are predisposing factors for the development of bacterial diseases in reptiles. Probably, due to the factors that predispose to infection by these bacterial agents, most reports on stomatitis in serpents approach cases occurred in captive animals, differently from what has been presented in this case, which is about a free animal rescued when invading an urban area. The bacteria isolated from the oral cavity of the serpent here reported belong to the normal microbiota of the oral cavity of these animals. Notwithstanding, these bacteria may become pathogenic in certain circumstances. Conditions of undernutrition, stress and oral trauma are considered as predisposing factors to the occurrence of stomatitis in serpents, what can be correlated to the occurrence of the disease in this case. The gram-negative agents causing bacterial diseases in serpents are generally resistant to medicines of the most common spectrum used in the clinical routine of wild animals. Furthermore, veterinary literature reported that most of serpent stomatitis cases lead to death, since in late care septicemia is frequent, with involvement of the face bones and central nervous system. This way, veterinarians often deal with these diseases in reptiles empirically, using a wide range of antibiotics. This practice might result in the development of resistant bacterial stumps, what stands out due to the potential that resistant bacteria have to generate infections and zoonoses in humans.
\end{abstract}

Keywords: bacterioses, stomatitis, snakes. contagiosas (LADOC), Universidade Federal de Uberlândia (UFU), Uberlândia, MG, Brazil. CORRESPONDENCE: R.R. Souza [rafael.souza@ufu. br - Tel.: +55 (34) 996420015]. Faculdade de Medicina Veterinária (FAMEV), Universidade Federal de Uberlândia (UFU). Av. Mato Grosso n. 3289 - Bloco 2S. Bairro Umuarama. CEP 38405-314 Uberlândia, MG, Brazil. 


\section{INTRODUCTION}

Stomatitis is one of the most common disorders in serpents, characterized by the infection of the oral mucosa and neighboring tissues. It is related to the opportunistic character of the bacteria present in the normal microbiota and that can be pathogenic in stressful situations [6]. It can be predisposed by traumatic injuries and the injury can then be colonized by opportunistic bacteria $[3,6]$.

The green anaconda (Eunectes murinus) is a non-poisonous and constrictor serpent, Squamata order (suborder Ophidia), family Boidae, of diurnal and nocturnal habits, that can be aquatic or earthly [8]. It is the largest species of serpent in Brazil and the second largest in the world, being up to $10 \mathrm{~m}$ long [11]. In spite of the high frequency of stomatitis in serpents, few studies have described this alteration in serpents from the Brazilian fauna. Assessments of its profiles of sensibility and resistance are also very scarce [12].

Among the bacterial diseases in serpents, the ones caused by gram-negative agents stand out, which, in most cases, are resistant to medicines of a broad spectrum most commonly used in the clinical routine of wild animals [4]. This way, veterinarians often deal with these diseases in reptiles empirically, using a wide range of antibiotics, what can lead to the development of resistant stumps in the bacteria [5].

Consequently, the aim of this study has been to describe the isolation and identification of the infectious agents involved in the clinical stomatitis in a specimen of green anaconda (Eunectes murinus) and the profile of sensibility and resistance to the antimicrobial agents found.

\section{CASE}

A specimen of Eunectes murinus, popularly known as green anaconda, female, adult, coming from the natural environment, without previous records, has been rescued in an urban environment by the Environmental Police and led to the Laboratory of Teaching and Research on Wild Animals of the Veterinarian Hospital of the Federal University of Uberlândia.

In a clinical evaluation, it has been assessed that the specimen had erosive injuries in its oral cavity, with hyperemic points in its mucosa and serous secretion (Figure 1).

Then the specimen went through a collection of the secretion from its oral cavity The sample has been stored and sent to the Laboratory of Infectious Diseases of the Universidade Federal de Uberlândia.

Following aerobic culture routine, the isolates were plated and incubated at $37^{\circ} \mathrm{C}$ for $24-48 \mathrm{~h}$. Based on the acquired colonies, the isolates were further determined by colony morphology, Gram stain and biochemical tests: Phenol red, Lysine, Phenylalanine, Citrate, Urea and SIM (Sulfuric Acid, Indole and Motility), and test of Oxidation-Fermentation [13].

The profile of susceptibility to antimicrobials of the isolated microorganisms has been determined through the method of diffusion in the disk of Kirby-Bauer [9]. The antimicrobials were employed in the study: Penicillin, Enrofloxacin, Amikacin + Clavulanate, Ceftiofur, Ampicillin, Gentamicin (all Sensifar- Vet $\left.^{\circledR}\right)^{1}$ and Ciprofloxacin ${ }^{2}\left(\text { Sensibiodisc }^{\circledR}\right)^{2}$.

After the cultivation, three colonies of Enterococcus sp., Citrobacter freundii and Enterobacter sp. have been identified [13]. There was not any sensitive antimicrobial for the three agents. Enterococcus sp. was sensitive only to penicillin, amoxicillin with clavulanate and ampicillin, being resistant to amikacin and ceftiofur. Citrobacter freundii was sensitive only to ciprofloxacin; and Enterobacter sp. was the bacteria with the highest antimicrobial susceptibility compared to the other microorganisms, being sensitive to ciprofloxacin, amikacin, ceftiofur and gentamicin.

Based on the antimicrobial profile presented, the treatment has been carried out with intramuscular Ciprofloxacin $(5 \mathrm{mg} / \mathrm{kg})$, associated to daily washings with solution of chlorhexidine $0.12 \%$, during 10 days, subsequently, in the clinical reassessment, a complete

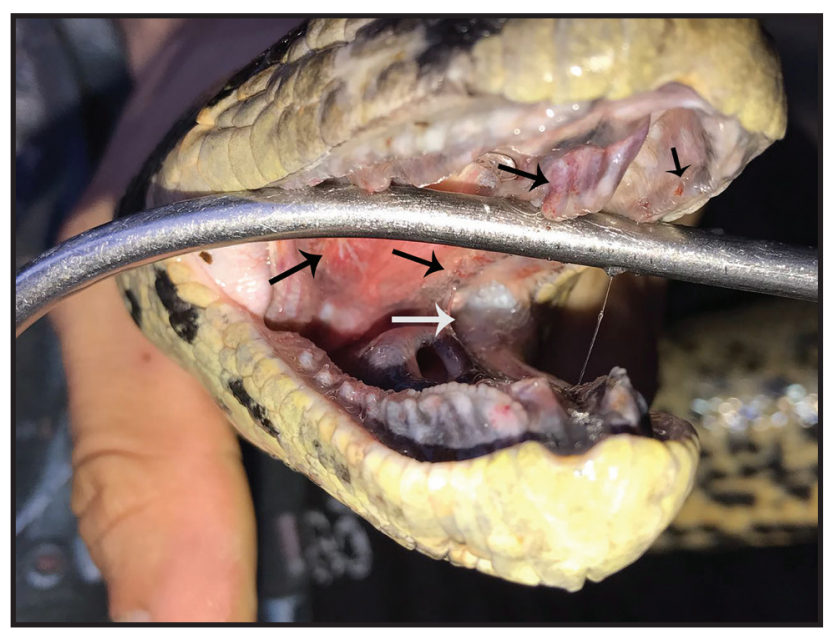

Figure 1. Serpent of the species Eunectes murinus featuring injuries in its oral cavity, with hyperemic areas in the mucosa (black arrows) and the presence of translucid secretion (white arrow). 
N.B. Martins, L.A.R. Ferreira, A.L.Q. Santos, et al. 2019. Green Anaconda (Eunectes murinus) with Bacterial Clinical

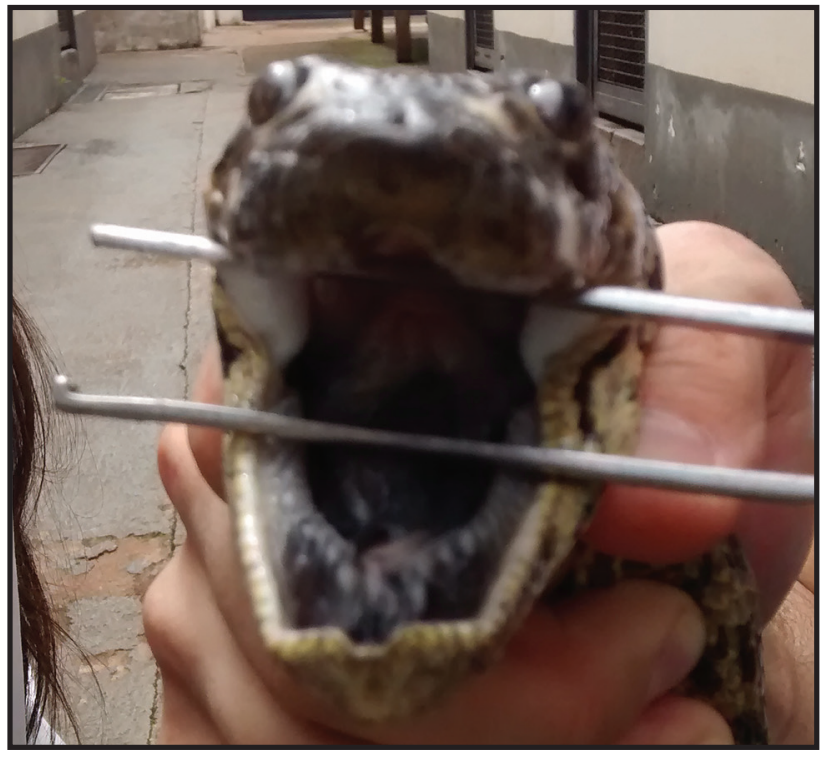

Figure 2. Serpent of the species Eunectes murinus the complete remission of the lesions in the oral cavity and consequent reepithelialization.

remission of erosive lesions of the oral mucosa was observed and its full re-epithelialisation (Figure 2).

\section{DISCUSSION}

Despite the high frequency of stomatitis in serpents and the influence of bacteria in these animals, as well as the influence of those bacteria on human beings, the studies about the characterization and distribution of those microorganisms are scarce [1]. The reports on this alteration on serpents of the Brazilian fauna are also rare [12].

Stomatitis is commonly observed in large species of constrictor serpents [11], as the one related to this case. Although the microorganisms most prone to cause infections in these animals are Aeromonas hydrophila, Pseudomonas spp., Proteus spp., Salmonella spp., Escherichia coli, Providencia spp., Xanthomonas maltophila and Enterobacter spp. [8], stumps of Enterococcus spp. and Citrobacter freundii have already been isolated from bites caused by vipers (Trimeresurus mucrosquamatus e Trimeresurus stejnegeri) [2]. Enterobacter spp. is the bacterium most associated to abscedative illnesses and oral infections in these animals [7].

The bacteria isolated from the oral cavity of the serpent here reported belong to the normal microbiota of the oral cavity of these animals. Notwithstanding, these bacteria may become pathogenic in certain circumstances. Conditions of undernutrition, stress and oral trauma are considered as predisposing factors to the occurrence of stomatitis in serpents [6-8], what can be correlated to the occurrence of the disease in this case.

Most reports on stomatitis in serpents approach cases occurred in captive animals $[3,10,12]$, differently from what has been presented in this case, which is about a free animal rescued when invading an urban area. As a matter of fact, a higher predisposition to the occurrence of this disease is observed in captive animals, when compared to the free ones $[7,8]$.

Of the bacteria involved in the case described above, two were gram-negative (Enterobacter sp. e Citrobacter freundii) and one was gram-positive (Enterococcus sp.). The gram-negative agents causing bacterial diseases in serpents are generally resistant to medicines of the most common spectrum used in the clinical routine of wild animals. This way, veterinarians often deal with these diseases in reptiles empirically, using a wide range of antibiotics [4]. This practice might result in the development of resistant bacterial stumps [5], what stands out due to the potential that resistant bacteria have to generate infections and zoonoses in humans [1].

Usually, the cases of stomatitis in serpents feature harsh complications, leading the animal to death, since that in cases of late clinical intervention, the occurrence of septicemia is possible [6], or the inflammation can reach the bones of the face and the central nervous system [3]. The success of the antimicrobial treatment here observed can be referred to the precocity of its occurrence, as well as the establishment of the treatment only after the identification and evaluation of the profile of sensibility and resistance of the involved agents.

No antimicrobial has been sensitive to all agents causing stomatitis in the described species. The reports on this disease are scarce when it comes to species of the Brazilian fauna, what makes necessary the characterization of its agents for the adequate therapeutic conduct, since indiscriminate antimicrobial treatments may induce resistance to drugs and compromise the treatment of individuals with serious diseases, being also prone to be transmitted to humans.

\section{MANUFACTURERS}

${ }^{1}$ Cefar Diagnóstica. São Paulo, SP, Brazil.

${ }^{2} \mathrm{CECON}$ - Centro de Controle e Produtos para Diagnóstico. São Paulo, SP, Brazil.

Declaration of interest. The authors report no conflicts of interest. The authors alone are responsible for the content and writing of the paper. 


\section{REFERENCES}

1 Artavia-León A., Romero-Guerrero C., Sancho-Blanco N. \& Umanã-Castro R. 2017. Diversity of aerobic bacteria isolated from oral and cloacal cavities from free-living snakes species in Costa Rica Rainforest. International Scholarly Research Notices. 17: 1-9.

2 Chen C.M., Wu K.G., Chen C.J. \& Wang C.M. 2011. Bacterial infection in association with snakebite: A 10-year experience in a northern Taiwan medical center. Journal of Microbiology, Immunology and Infection. 44(6): 456-460.

3 Czirják G.A., Köbölkuti L.B., Tenk M., Szakacs A., Kelemen A. \& Spinu M. 2015. Hemorrhagic stomatitis in a natural hybrid of Vipera ammodytes x Vipera berus due to inappropriate substrate in terrarium. Journal of Veterinary Medical Science. 77(6): 701-703.

4 Ferreira P.R.B., Curvelo L.Q.S., Gondim G.O., Santana G.O. \& Oliveira A.V.D. 2014. Sinais clínicos e alterações necroscópicas em filhotes de Eunectes murinus (Linnaeus, 1758) infectados com bactérias Gram negativas multirresistentes. Jornal Brasileiro de Ciência Animal. 7(14): 508-522.

5 Foti M., Giacopello C., Fisichella V. \& Latella G. 2013. Multidrug-resistant Pseudomonas aeruginosa isolates from captive reptiles. Journal of Exotic Pet Medicine. 22(3): 270-274.

6 Grego K.F., Carvalho M.P.N., Cunha M.P.V., Knöblb, T., Pogliani F.C., Catão-Dias J.L., Sant'Anna S.S., Ribeiro M.S. \& Sellera F.P. 2017. Antimicrobial photodynamic therapy for infectious stomatitis in snakes: Clinical views and microbiological findings. Photodiagnosis and Photodynamic Therapy. 20: 196-200.

7 Jacobson E.R. 2007. Bacterial diseases of reptiles. In: Jacobson E.R. (Ed). Infectious diseases and pathology of reptiles: color atlas and text. New York: CRC Press, pp.461-562.

8 Kolesnikovas C.K.M., Grego K.F. \& Rahme-de-Albuquerque L.C. 2014. Répteis - Ordem Squamata - Subordem Ophidia. In: Cubas Z.S., Silva J.C.R. \& Catão Dias J.L. (Eds). Tratado de animais selvagens - Medicina veterinária. São Paulo: Roca Ltda., pp.68-85

9 Koneman E.W., Allen S.D., Janda W.M., Schreckenberger P.C. \& Winnn Jr. W.C. 2010. Provas de sensibilidade e agentes antimicrobianos. In: Diagnóstico Microbiológico: Texto e Atlas Colorido. 6.ed. Rio de Janeiro: Guanabara Koogan, pp.940-1014.

10 Marschang R.E., Heckers K.O., Dietz J. \& Kolesnik E. 2016. Detection of a Mycoplasma sp. in a Python (Morelia spilota) with Stomatitis. Journal of Herpetological Medicine and Surgery. 26: 90-93.

11 Mendyk R.W. 2015. History and Fate of a Troubled Reptile Zoo: The Long Island Reptile Museum. Herpetological Review. 46(4): 547-555.

12 Pereira H.C., Gomes D.O., Hirano L.Q.L., Santos A.L.Q. \& Lima A.M.C. 2017. Oral microbiota in healthy Bothrops atrox (Serpentes: Viperidae) and in snakes with stomatitis. Acta Veterinaria Brasilica. 11: 180-183.

13 Quinn P.J., Markey B.K., Leonard F.C., Fitz Patrick E.S. \& Fanning S. 2015. Concise Review of Veterinary Microbiology. 2nd edn. Ames: Wiley Blackwell, 199p.

14 Reed R.N. \& Rodda G.H. 2009. Giant constrictors: biological and management profiles and an establishment risk assessment for nine large species of pythons, anacondas, and the Boa constrictor. US Geological Survey, Reston, Virginia, pp.142-186. [Fonte: < https://pubs.usgs.gov/of/2009/1202/pdf/OF09-1202.pdf>]. [Acessed online in July 2018]. 